\title{
Archila, M. (coord.); Arboleda, Z.; Coronado, S. et al. (2015). "Hasta cuando soñemos", Extractivismo e interculturalidad en el sur de La Guajira. Bogotá: Cinep.
}

Por Alejandro Angulo S.J. ${ }^{1}$

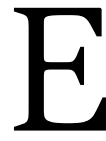
ste libro tiene un título de largo alcance del que no sé si los autores fueron conscientes. "Hasta cuando soñemos" no es solamente el plazo que los wayúu le dan al Cerrejón para hacer la consulta previa, sino que también es el que nosotros le podemos dar a la duración de la especie de los mamíferos racionales: seremos humanos hasta cuando soñemos. Cuando esto finalice, nos convertiremos en robots de carne y hueso, y el tremendo vaticinio de Aldous Huxley en su Mundo Mejor se habrá cumplido: habremos escogido la locura de vivir en utopía sobre la insania de vivir en un poblado indio. El libro que tenemos entre manos nos deja ver que el dilema de Huxley no es mera ciencia ficción.

¿Por qué? Por dos razones que configuran el argumento vertebral de la publicación: el del conocimiento científico y el de las relaciones humanas.

Archila et al. insisten, con sobrada razón, en que para conocer algo hay que haber tenido un contacto inmediato y activo con ese objeto. El que 
no hace nada no conoce nada. Ellos concretan esta conclusión mostrando cómo el investigador que no se compromete con la solución del problema ajeno y no trabaja codo a codo con quienes padecen ese problema no encontrará ninguna solución que valga la pena. Pero comprometerse con el problema ajeno añade, desde luego, el inconveniente de las relaciones humanas. De suerte que para resolver cualquier cuestión social se supone que tenemos resuelto el problema del conocimiento humano y que, además, conocemos alguna forma de resolver las dificultades que surjan de las relaciones humanas. Ninguna de esas dos condiciones crece salvaje. Ambas requieren trabajo cuidadoso y un cultivo continuo. Y como ambas son un problema de lenguaje, nuestros autores llegan, sin poderlo evitar, a la interculturalidad. La manera en que el libro aborda todas estas cuestiones es muy sugerente.

En la primera parte, que en la obra llaman “teoría”, se narra y se discute la historia del diálogo de saberes, que es el mínimo que una persona educada puede practicar cuando encuentra a otra, pero que no siempre es el caso, como el libro lo demuestra con amplitud y erudición. Numerosos científicos sociales creyeron y siguen creyendo, como lo narran con lujo de detalles los autores, que pueden entender y resolver los problemas usando como única base sus propios prejuicios y desvirtuando los ajenos. Tales personajes también suelen creer en la acción social a distancia. La Guajira se puede arreglar desde Bogotá. Falso. Esta creencia errónea conlleva la otra hipótesis igualmente falsa de que los estudios superiores preparan para resolver algún problema de la vida real, afirmación que, con frecuencia, lleva a menospreciar a los que sufren el problema y que son los únicos que lo pueden resolver.

Esas dos falsedades suelen ir encadenadas y desvirtúan, si no todos, buena parte de los planes de desarrollo del país. Los autores presentan y discuten agudamente las vicisitudes de dichas hipótesis y señalan sus contradicciones palmarias que se explican, con facilidad, si uno tiene en cuenta, las deficiencias de nuestro sistema escolar de una parte, y de otra, la forma cómo las luchas de poder contaminan la academia y su ciencia. 
En este sentido es interesante y divertido leer la forma como lo autores describen las dificultades de muchos colegas y funcionarios para entender el pensamiento indígena. Y resultan muy útiles sus insinuaciones de que para la resolución de problemas sociales son más eficaces el diálogo de saberes y el interculturalismo que la planificación central y la presunción clasista. La razón obvia es el absurdo de pretender imponer una respuesta prefabricada en otro lugar a una cuestión que el autoritario analista ni siquiera entiende, porque desconoce el lenguaje requerido para trazar un diagnóstico medianamente aproximado de la situación y formular unas recomendaciones que le sirvan a los ejecutores del plan.

Una de las buenas contribuciones del libro es que trae ejemplos claros de los distintos lenguajes que las personas usan para expresar sus ideas y ponderar sus dificultades. Cotejando las diversas narrativas, se concluye cómo en asuntos de importancia trascendental para el país, y también para la humanidad, se sustituye el diálogo de sordos al diálogo de saberes, y se deja en evidencia que no hay peor sordo que el que no quiere oír. Como es obvio, detrás esa sordera culposa se agazapa una pugna de intereses y se manifiestan fallas éticas vergonzosas que provienen en general de ignorancia supina o de mala fe. Ponerlas en evidencia es un primer paso que dan los autores en su obra. Intercomunicar esos lenguajes es harina de otro costal.

El libro sugiere la traducción de un lenguaje al otro, pero con toda razón coloca la palabra traducción entre comillas, no sea que se malinterprete, dado que el problema de fondo de la traducción de una lengua a otra sigue enfrentando el reto de no cometer traición; en cambio, al enmarcar el tema de los lenguajes en el capítulo de la interculturalidad, se ilustran las dificultades intrínsecas del traducir y se revela cómo la incomprensión entre culturas es un asunto de lenguaje. Con gran acierto, la discusión hace justicia al pragmatismo wayúu de recurrir al multiculturalismo mientras claman por un diálogo intercultural, aparente incoherencia que también practican los colegas académicos, como lo 
confiesan los autores. De esta forma, dejan en claro que la distinción entre multiculturalismo e interculturalismo tiene algo de juego de abalorios y que la solución viene por el lado del pragmatismo.

Con todo, en el libro sí se insinúan los prejuicios a los que cada grupo se aferra para defender su opinión. Esta me parece la contribución más interesante, porque se clasifica a los multiculturales como liberales y a los interculturales como equitativos, subrayando así la raíz ideológica de la discusión. En la misma línea de develar ideologías se afirma que los multiculturales son los del norte, los hegemónicos son del occidente, y los interculturales son los contrahegemónicos o los del sur. Esto creo que habría que precisarlo. Queda, pues, bien patente que las traducciones son imposibles cuando todas las palabras van siempre cargadas y que lo que habría que buscar es crear las condiciones para una negociación cultural que comience por colocar los propios prejuicios sobre la mesa y ponerles un rótulo con su precio verdadero. Los autores dan el ejemplo en esta primera parte.

Pero es en la segunda parte donde muestran el candor necesario para contar con toda lealtad los resultados de las propias experiencias, franqueza que, a mi juicio, es la cualidad más valiosa de un investigador serio. En esta parte aparece con claridad lo que conlleva un encuentro de culturas y se palpa la nítida prioridad de los sentimientos sobre los pensamientos. Este orden de los procesos de la mente es difícil de manejar porque, en primer lugar, de eso no se habla, y, en segundo lugar, para esquivar los desencuentros se requiere, como diría el Machiavelli, fortuna y virtud, lo cual también se puede expresar de la siguiente forma: para el encuentro de culturas, la paciencia es más importante que la ciencia. Por desgracia, esto tampoco se enseña en la academia.

Pero en el libro sí se consigna que todo resultó "bien por lo conformes”. O en otras palabras, que ambas partes manifiestan las unas a las otras que aprendieron muchísimo, a pesar de que entendieron que hay dificultades, la menor de las cuales es que cada lado podía refugiarse en su 
lenguaje cuando lo juzgaba necesario. Las verdaderas dificultades, sin duda, son el cambio de cosmogonías cuando se refieren al territorio, la transformación de las cosmologías cuando estudian la organización y el choque de cosmovisiones cuando discuten acerca del desarrollo. Ninguna de las tres parecería ser negociable y, por consiguiente, el resultado de las conversaciones sobre ordenamiento territorial, sobre igualdad democrática y sobre economía política no aspira a ir más allá de lo posible, es decir, la recíproca convicción de que se hizo lo que se pudo. Porque como aparece con claridad en la parte práctica del libro, que es la tercera, las circunstancias del país, con sus inequitativos modelos económico, político y social, vuelven muy complicada la solución de los problemas por la vía racional. Esto se manifiesta sin ambages en la discusión sobre la consulta previa, sobre la inversión multinacional, sobre los planes nacionales de desarrollo, en los cuales aparece una vez más que los asuntos de lenguaje son fundamentales, porque en las palabras viaja la trampa; y que una cultura de máxima racionalidad individual y mínima o ninguna racionalidad colectiva está sobredeterminada a verificar la ley natural de que los peces chicos tienen que contentarse con dejarse devorar por las ballenas y los tiburones. 